\title{
Long-Term Quality of Life after
} Endoscopic Pituitary Adenoma Surgery with Nasoseptal Flap Reconstruction

\author{
Shadi Shinnawi, M.D. ${ }^{1,2}$, Ilya Kopaev, M.D. ${ }^{1}$, Shorook Na’ara, M.D., Ph.D. ${ }^{1,2}$, \\ Ayelet Eran, M.D. ${ }^{3}$, Gil Sviri, M.D. ${ }^{4}$, Dmitry Ostrovsky, M.D. ${ }^{1}$, and Ziv Gil, \\ M.D., Ph.D. ${ }^{1,2 *}$ \\ ${ }^{\prime}$ Department of Otolaryngology-Head and Neck Surgery, Rambam Health Care Campus, Haifa, Israel; \\ ${ }^{2}$ The Laboratory for Applied Cancer Research, Rambam Health Care Campus, Haifa, Israel; ${ }^{3}$ Department \\ of Radiology, Rambam Health Care Campus, Haifa, Israel; ${ }^{*}$ Department of Neurosurgery, Rambam \\ Health Care Campus, Haifa, Israel
}

\begin{abstract}
Introduction: Endoscopic endonasal transsphenoidal surgery (EETS) on the pituitary gland is considered safe and efficacious. The nasoseptal flap (NSF) is sometimes used to prevent or repair postoperative cerebrospinal fluid (CSF) leaks. Few investigators have quantified long-term quality-of-life (QOL) outcomes regarding sinonasal measures after EETS, with or without involvement of the NSF. This study assesses whether the septal flap affects sinonasal QOL outcomes for patients receiving EETS for pituitary adenoma.

Methods and Materials: This is a retrospective study of patients who underwent EETS between 2013 and 2018. A total of 62 adults completed the Sinonasal Outcome Test-22 (SNOT-22) at least one year after the surgery. Outcome measures were compared between patients who underwent EETS with and without septal flap reconstruction.
\end{abstract}

Abbreviations: EETS, endoscopic endonasal transsphenoidal surgery; CSF, cerebrospinal fluid; NR, no reconstruction; NSF, nasoseptal flap; NSFR, nasoseptal flap reconstruction; QOL, quality of life; SNOT-22, Sinonasal Outcome Test-22.

Citation: Shinnawi S, Kopaev I, Na'ara S, Eran A, Sviri G, Ostrovskya D, Gil Z. Long-Term Quality of Life after Endoscopic Pituitary Adenoma Surgery with Nasoseptal Flap Reconstruction. Rambam Maimonides Med J 2021;12 (2):eo013. doi:10.5041/RMMJ.10435

Copyright: (C) 2021 Shinnawi et al. This is an open-access article. All its content, except where otherwise noted, is distributed under the terms of the Creative Commons Attribution License (http://creativecommons.org/licenses/by/3.o), which permits unrestricted use, distribution, and reproduction in any medium, provided the original work is properly cited.

Acknowledgments: We thank Steve Spencer for his editorial assistance.

Conflict of interest: No potential conflict of interest relevant to this article was reported.

* To whom correspondence should be addressed. E-mail: g_ziv@rambam.health.gov.il 
Results: For the entire cohort, there were 14 patients (22.6\%) who had septal flap reconstruction and 48 patients (77.4\%) who did not. Patient demographics, tumor characteristics, surgical outcomes, and duration between surgery and completion of the questionnaire were similar for both groups. The mean SNOT-22 scores in the no reconstruction (NR) group and the nasoseptal flap reconstruction (NSFR) group were similar $(P=0.9)$. In terms of SNOT-22 subdomains (rhinologic symptoms, extranasal rhinologic symptoms, ear/facial symptoms, psychological dysfunction, and sleep dysfunction), no significant differences were found when comparing the groups.

Conclusion: As compared with no reconstructive involvement, NSF utilization does not affect the QOL and nasal symptoms of patients undergoing EETS.

KEY WORDS: Endoscopic pituitary adenoma surgery, nasoseptal flap reconstruction, quality of life

\section{INTRODUCTION}

Over the last century, pituitary adenoma surgery has evolved from transcranial approaches to less invasive transsphenoidal approaches. ${ }^{1}$ Modern endoscopic pituitary surgery was introduced in France in 1992 and in the United States in 1997.2,3 In more recent years, this endoscopic technique has become widely accepted by otolaryngologists and neurosurgeons around the world, and its efficacy, safety, advantages, and disadvantages have been evaluated in numerous studies. ${ }^{-10}$

The nasoseptal flap (NSF) is a neurovascularized mucoperichondrial and mucoperiosteal axial pattern flap, which is situated on the posterior branch of the sphenopalatine artery. ${ }^{11}$ It is used commonly as part of the reconstructive phase of endoscopic pituitary surgery, primarily to prevent and/or seal cerebrospinal fluid (CSF) leaks, as well as to reconstruct the surgical defect to provide a healthy nasal microenvironment. ${ }^{12}$ However, the impact of the nasoseptal flap reconstruction (NSFR) on nasal function due to manipulation of nasal mucosa has been a major concern, as nasal complications such as crusting, septal perforation, and cartilage necrosis have accompanied endoscopic endonasal approaches and NSF utilization. ${ }^{13,14}$ These complications and their impacts on quality of life (QOL) have been the subject of investigations by several authors. ${ }^{15-20}$

The Sinonasal Outcome Test-22 (SNOT-22) questionnaire is a validated, patient self-assessment tool, which measures symptom severity and healthrelated QOL issues as they relate to sinonasal conditions. ${ }^{21,22}$ Although not specifically designed for this purpose, SNOT-22 has been used in several recent studies to evaluate the impact of endoscopic endonasal skull base approaches on the QOL of patients with skull base pathologies. ${ }^{15,16,23,24}$ However, to date, little has been published on long-term QOL outcomes, specifically sinonasal measures following endoscopic endonasal transsphenoidal surgery (EETS). Accordingly, in this study, we focus on comparing postoperative SNOT-22 QOL measures between patients who underwent EETS for pituitary adenoma with NSFR and those who underwent the surgery with no reconstruction.

\section{MATERIALS AND METHODS}

The study is based on a review of the hospital charts of and questionnaire responses from patients that underwent EETS during the years 2013-2018, and who had pathology reports compatible with pituitary adenoma. All surgeries were performed by the same interdisciplinary team at the Rambam Health Care Campus in Haifa, Israel.

Eligible patients for study inclusion were over 18 years of age who underwent EETS for pituitary adenoma at least 12 months prior to the study. Exclusion criteria were as follows: (1) the existence of other skull base lesions; (2) pre-existing sinus disease; (3) nasal allergies; (4) intranasal drug abuse; (5) subjective olfactory disturbance at baseline; or (6) previous transsphenoidal pituitary surgery.

\section{Questionnaire}

Patients were surveyed a single time, postoperatively, via mobile phone using the SNOT-22, which is an adaptation of prior, disease-specific instruments that have been validated in the otolaryngology literature. ${ }^{21,25-27}$ The SNOT-22 contains 22 items divided into five domains (rhinologic symptoms, extranasal rhinologic symptoms, ear/facial symptoms, psychological dysfunction, and sleep dysfunction). ${ }^{28}$ Items are scored on a $0-5$ scale, where 0 reflects "no problems" and 5 indicates a "problem as bad as it can 
be." Total scores can range from o to 110, with higher scores indicating worse QOL.

\section{Surgical Approach}

Preparation and initial steps are critical to the success of NSF harvesting. Prior to elevation of the NSF, topical and local decongestants are used. Bilateral out-fracturing of inferior turbinates are carried out, and the sphenoid ostium is exposed. After inspection of the nasal cavity, the middle turbinate on one side is resected in its caudal part. At this stage, the NSF is elevated. With the use of a scalpel, the first incision is performed along the junction of the lower border of the nasal septum from posterior to anterior. Posteriorly, the incision reaches the choana and curves along its superior edge toward the medial maxillary wall. Superiorly, the incision reaches below the sphenoid ostium and curves superior to the sphenopalatine artery. Anteriorly, the incisions should reach the limen nasi. The edges of the flap should be right angled to achieve maximal coverage of the flap. Next, using a Freer retractor, the flap is meticulously elevated laterally up to the level of the sphenopalatine foramen. It is then stored in the choana or in the maxillary antrum. ${ }^{29}$

\section{Ethical Considerations}

The study was conducted after its protocol was approved by the Helsinki Committee review board at our institution.

\section{Statistical Analysis}

The results are presented as mean $\pm \mathrm{SD}$ for quantitative variables and number for categorical variables. Fisher's exact test and $t$ test were applied for comparison of categorical and quantitative variables, respectively. All statistical assessments were 2-sided and evaluated at the 0.05 level of significant difference, using IBM SPSS Statistics 22 for Mac (IBM Corporation, Armonk, New York, USA).

\section{RESULTS}

Ninety-one patients were eligible for enrollment in this study. The response rate for completing the questionnaire-after excluding those patients who died, who were lost to follow-up, or who were operated on $<12$ months before the study beganwas $68.1 \%$. Thus, 62 patients participated (50\% male and 50\% female; ranging in age from 19 to 81 years, with a mean age of $51.58 \pm 15.16$ years), completing the SNOT-22 $\geq 1$ year postoperatively.
Patients were divided into two groups according to the use or non-use of NSF for reconstruction of the skull base defect: 14 patients in the NSFR group, and 48 patients in the no reconstruction (NR) group. Among the former, 3 patients underwent the surgery less than 24 months before answering the questionnaire; among the latter, 16 patients underwent the surgery less than 24 months before answering the questionnaire, $P=0.51$. As shown in Table 1, demographic and clinical characteristics were similar between the groups.

All 62 patients underwent successful removal of a pituitary adenoma via the transsphenoidal endoscopic approach. Mean hospitalization time was 4.2 \pm 1.3 days, with no significant difference between the groups. There were no postoperative mortalities and no documented cases of CSF leakage, meningitis, tension pneumocephalus, or disease recurrence.

We first compared the mean overall postoperative SNOT-22 scores according to surgical approach employed. Patients in the NR group reported similar scores compared to the NSFR group (35.97 \pm 21.47 and $36.78 \pm 22.17$, respectively), $P=0.9$ (Figure 1). Next, in assessing the postoperative scores of subdomains, we found that for each there were no statistically significant differences between the groups (Table 2). Finally, in evaluating each of the SNOT-22 questionnaire items separately, we found that no significant differences existed between the groups (Figure 2).

\section{DISCUSSION}

Endoscopic endonasal transsphenoidal surgery is a widely accepted approach for pituitary tumor resections, and its safety and efficacy have been well documented in the literature. ${ }^{30-34}$ Nasoseptal flap reconstruction was introduced by Hadad et al. and has come into more common practice as an option for patients presenting large dural defects of the skull base following pituitary surgery. ${ }^{11}$ Assessments of QOL play an important role in evaluating the efficacy of surgical interventions, as the surgeon's perception of a patient's QOL has been shown to be inaccurate in the postoperative period. ${ }^{35-37}$ This retrospective analysis was conducted to determine the impact of NSFR in endoscopic pituitary adenoma surgery on patients' long-term QOL via an assessment of SNOT-22 questionnaire responses. In the present study, postoperative ( $\geq 12$ months) SNOT-22 
Table 1. Demographic and Medical Characteristics of the 62 Patients.

\begin{tabular}{|c|c|c|c|}
\hline \multirow[b]{2}{*}{ Characteristics } & \multicolumn{2}{|c|}{ No. (\%) of Patients } & \multirow[b]{2}{*}{$P$ Value } \\
\hline & $\begin{array}{l}\text { NSFR Group } \\
(n=14)\end{array}$ & $\begin{array}{c}\text { NR Group } \\
(n=48)\end{array}$ & \\
\hline \multicolumn{4}{|l|}{ Sex } \\
\hline Female & $9(64)$ & $22(46)$ & .36 \\
\hline Male & $5(36)$ & $26(54)$ & \\
\hline Age, $m e a n \pm S D, y$ & $52.35 \pm 15.82$ & $51.35 \pm 15.12$ & .82 \\
\hline \multicolumn{4}{|l|}{ Time from surgery, mo } \\
\hline$<24$ & $3(21)$ & $16(33)$ & .51 \\
\hline$\geq 24$ & $11(79)$ & $32(67)$ & \\
\hline \multicolumn{4}{|l|}{ Comorbidity } \\
\hline Yes & $5(36)$ & $16(33)$ & .99 \\
\hline No & $9(64)$ & $32(67)$ & \\
\hline Tumor size, mean $\pm S D, m m$ & $16.92 \pm 4.22$ & $19.17 \pm 7.34$ & .27 \\
\hline
\end{tabular}

NR, no reconstruction; NSFR, nasoseptal flap reconstruction; SD, standard deviation.

data were obtained and compared between a group of patients who underwent EETS for pituitary adenoma with NSFR and another group who underwent the same surgery with no reconstruction. The present data showed no statistically significant difference between the groups in overall mean SNOT-22 scores, SNOT-22 subdomain scores, or separate SNOT-22 item scores.

Following harvest of the pedicled NSF, both secretions and blood flow directly onto the exposed carti- lage and bone of the septum. The NSF donor site heals by secondary intention and can result in significant crusting for up to 12 weeks postoperatively. $13,38,39$ De Almeida et al. investigated the time to resolution of nasal crusting, comparing an NSFR cohort to patients who did not have an NSFR.13 Patients who had an NSFR did not have a significantly longer time to recovery than patients without an NSFR. In addition, complete remucosalization of the nasal septum after NSFR requires an average 10

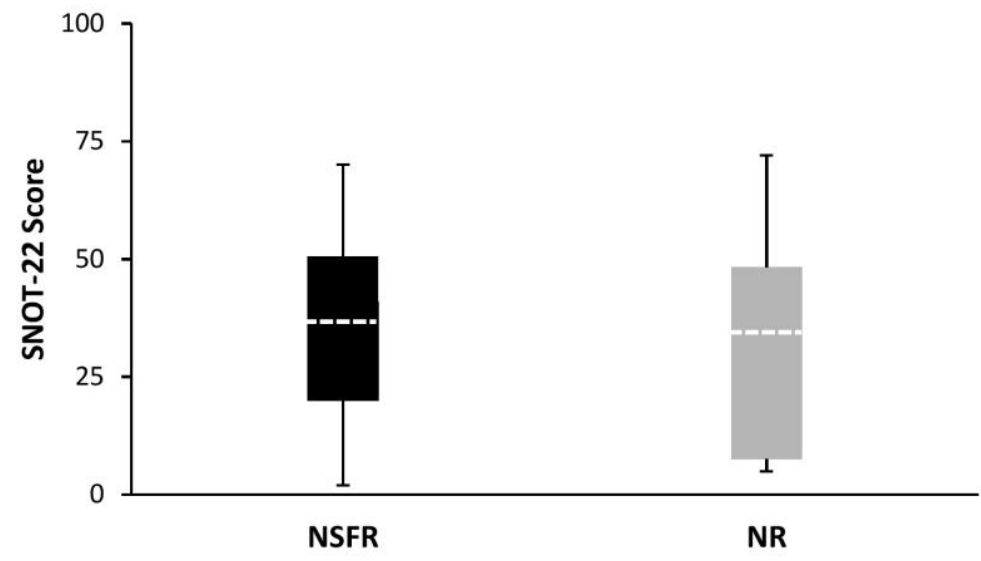

Figure 1. Comparison of Overall Sinonasal Outcome Test (SNOT-22) Scores Between the Two Surgical Groups. The horizontal dotted lines within the boxes represent the mean SNOT-22 score; the bottom and top lines of the boxes, the 25th and 75th percentiles; and the whiskers extending below and above the boxes, the minimum of the 25 th percentile and the maximum of the 75th percentile, respectively. 
Table 2. Postoperative ( $\geq 12$ months) Mean Sinonasal Outcome Test (SNOT-22) Subdomain Scores.

\begin{tabular}{|l|c|c|c|}
\hline \multirow{2}{*}{ Subdomain } & \multicolumn{2}{c|}{ Mean \pm SD } & \\
& $\begin{array}{c}\text { NSFR Group } \\
(\boldsymbol{n}=14)\end{array}$ & $\begin{array}{c}\text { NR Group } \\
(\boldsymbol{n}=48)\end{array}$ & $\boldsymbol{P}$ Value \\
\hline Rhinologic symptoms & $10.21 \pm 0.41$ & $9.00 \pm 0.44$ & 0.55 \\
\hline Extranasal rhinologic symptoms & $3.43 \pm 0.56$ & $4.04 \pm 0.34$ & 0.54 \\
\hline Ear/facial symptoms & $5.57 \pm 0.74$ & $6.42 \pm 0.40$ & 0.62 \\
\hline Psychological dysfunction & $13.57 \pm 0.52$ & $13.13 \pm 0.57$ & 0.88 \\
\hline Sleep dysfunction & $11.86 \pm 0.42$ & $10.88 \pm 0.40$ & 0.67 \\
\hline
\end{tabular}

NR, no reconstruction; NSFR, nasoseptal flap reconstruction.
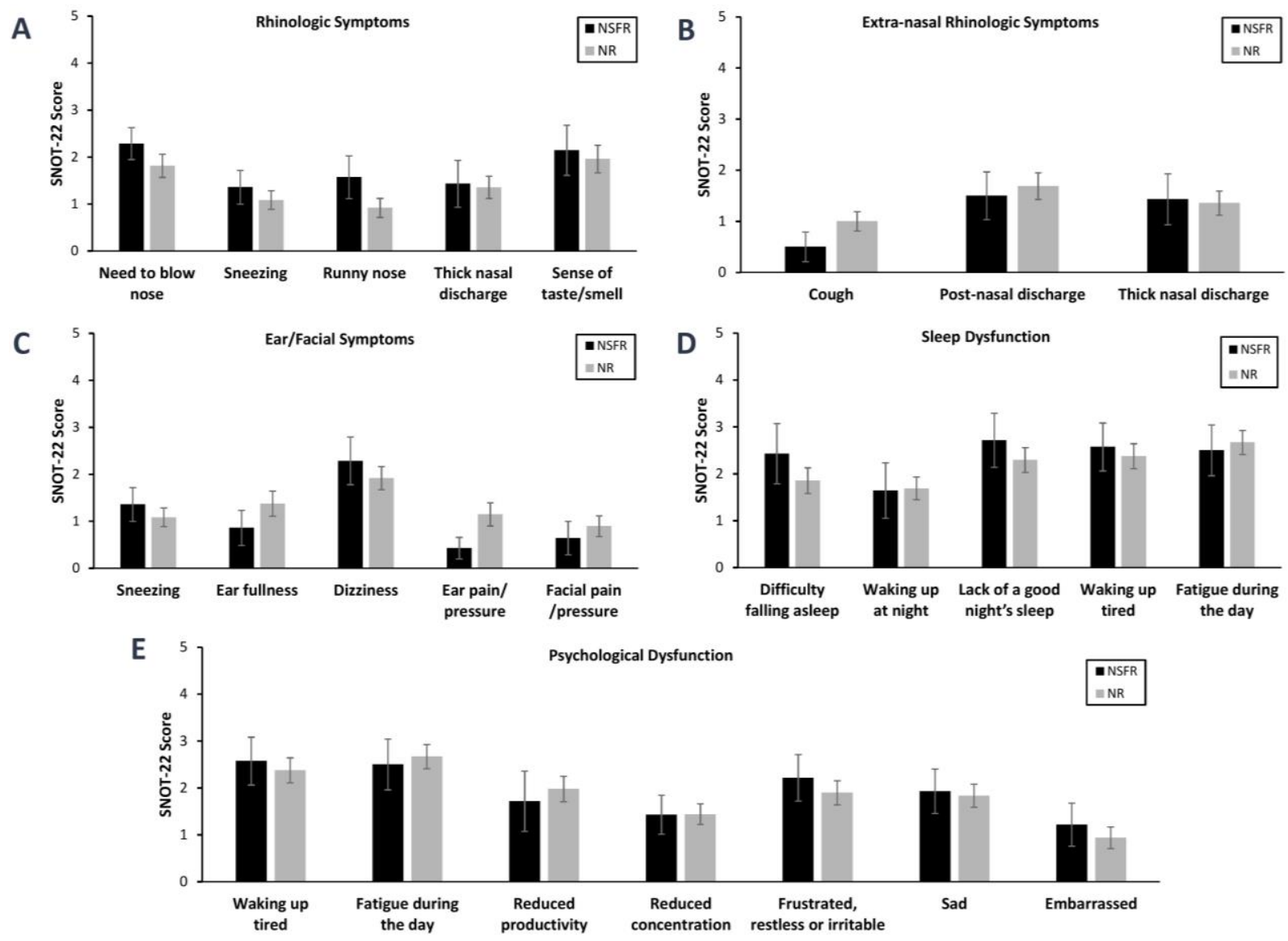

Figure 2. Comparison of Sinonasal Outcome Test (SNOT-22) Subdomain Scores Between the Two Surgical Groups.

A: Rhinologic symptoms. B: Extra-nasal rhinologic symptoms. C: Ear/facial symptoms. D: Sleep dysfunction. E: Psychological dysfunction.

Error bars indicate standard error. 
to 12 weeks. These data support that there should be no impact on long-term QOL in patients who underwent EETS for pituitary adenoma $>1$ year from surgery.

In a retrospective study by Pant et al., QOL was measured by Anterior Skull Base (ASB) and SNOT22 questionnaires. Results revealed a significant improvement in short-term QOL scores for patients who did not undergo NSFR as compared with those who did. ${ }^{15}$ These results may be explained by the fact that patients with larger tumors received NSFR. Moreover, the studied patients had various skull base pathologies, which may have affected research findings. However, limitations of the study design did not allow for conclusions about long-term changes in QOL to be drawn.

In contrast, the present sinonasal QOL study compared two groups with the same pathology and showed no significant differences between the groups. Regarding NSF use, a study by McCoul et al. showed no significant differences in ASB questionnaire scores recorded at 6 months postoperatively. Those findings are compatible with the results of this study, ${ }^{16}$ with the exception that the former did not carry out an assessment of long-term QOL data.

Our study was limited by a relatively small sample size (62 patients). Large-sample studies should be carried out to further evaluate QOL following EETS for pituitary adenoma. Moreover, it should be taken into consideration that there may be some element of selection bias in this study because only those patients who filled out surveys were included in the analysis. Unfortunately, the retrospective nature of this study did not permit a standardized time of administration of postoperative questionnaires.

\section{CONCLUSIONS}

Our results indicate that NSFR in EETS for pituitary adenoma do not mandate poorer long-term postoperative sinonasal QOL outcomes, compared to no reconstruction.

\section{REFERENCES}

1. Doty RL. Olfaction. Annu Rev Psychol 2001;52:42352. $\underline{\text { CrossRef }}$

2. Jankowski R, Auque J, Simon C, Marchal JC, Hepner H, Wayoff M. Endoscopic pituitary tumor surgery. Laryngoscope 1992;102:198-202. CrossRef
3. Jho HD, Carrau RL. Endoscopy assisted transsphenoidal surgery for pituitary adenoma. Technical note. Acta Neurochir (Wien) 1996;138:1416-25. CrossRef

4. Jho HD, Carrau RL. Endoscopic endonasal transsphenoidal surgery: experience with 50 patients. $\mathrm{J}$ Neurosurg 1997;87:44-51. CrossRef

5. Cappabianca P, Cavallo LM, Colao A, et al. Endonasal transsphenoidal approach: outcome analysis of 100 consecutive procedures. Minim Invasive Neurosurg 2002;45:193-200.

6. Cappabianca P, Cavallo LM, Colao A, De Divitiis E. Surgical complications associated with the endoscopic endonasal transsphenoidal approach for pituitary adenomas. J Neurosurg 2002;97:293-8. CrossRef

7. Jane JA Jr, Han J, Prevedello DM, Jagannathan J, Dumont AS, Laws ER. Perspectives on endoscopic transsphenoidal surgery. Neurosurg Focus 2005;19: E2. CrossRef

8. Kabil MS, Eby JB, Shahinian HK. Fully endoscopic endonasal vs. transseptal transsphenoidal pituitary surgery. Minim Invasive Neurosurg 2005;48:348-54. CrossRef

9. Nasseri SS, Kasperbauer JL, Strome SE, McCaffrey TV, Atkinson JL, Meyer FB. Endoscopic transnasal pituitary surgery: report on 180 cases. Am J Rhinol 2001;15:281-7. CrossRef

10. White D, Sonnenburg R, Ewend M, Senior B. Safety of minimally invasive pituitary surgery (MIPS) compared with a traditional approach. Laryngoscope 2004;114:1945-8. $\underline{\text { CrossRef }}$

11. Hadad G, Bassagasteguy L, Carrau RL, et al. A novel reconstructive technique after endoscopic expanded endonasal approaches: vascular pedicle nasoseptal flap. Laryngoscope 2006;116:1882-6. CrossRef

12. Rotenberg BW, Saunders S, Duggal N. Olfactory outcomes after endoscopic transsphenoidal pituitary surgery. Laryngoscope 2011;121:1611-13. CrossRef

13. de Almeida JR, Snyderman CH, Gardner PA, Carrau RL, Vescan AD. Nasal morbidity following endoscopic skull base surgery: a prospective cohort study. Head Neck 2011;33:547-51. CrossRef

14. Soudry E, Psaltis AJ, Lee KH, Vaezafshar R, Nayak JV, Hwang PH. Complications associated with the pedicled nasoseptal flap for skull base reconstruction. Laryngoscope 2015;125:80-5. CrossRef

15. Pant H, Bhatki AM, Snyderman CH, et al. Quality of life following endonasal skull base surgery. Skull Base 2010;20:35-40. CrossRef

16. McCoul ED, Anand VK, Schwartz TH. Improvements in site-specific quality of life 6 months after endo- 
scopic anterior skull base surgery: a prospective study. J Neurosurg 2012;117:498-506. CrossRef

17. Cavel O, Abergel A, Margalit N, Fliss DM, Gil Z. Quality of life following endoscopic resection of skull base tumors. J Neurol Surg B Skull Base 2012;73:11216. CrossRef

18. Abergel A, Cavel O, Margalit N, Fliss DM, Gil Z. Comparison of quality of life after transnasal endoscopic vs open skull base tumor resection. Arch Otolaryngol Head Neck Surg 2012;138:142-7. CrossRef

19. Amit M, Margalit N, Abergel A, Gil Z. Fascia lata for endoscopic reconstruction of high-flow leaks: the champagne cork technique. Otolaryngol Head Neck Surg 2013;148:697-700. $\underline{\text { CrossRef }}$

20. Gil Z, Fliss DM. Quality of life in patients with skull base tumors: current status and future challenges. Skull Base 2010;20:11-18. $\underline{\text { CrossRef }}$

21. Piccirillo JF, Merritt MG Jr, Richards ML. Psychometric and clinimetric validity of the 20-item sinonasal outcome test (SNOT-20). Otolaryngol Head Neck Surg 2002;126:41-7. $\underline{\text { CrossRef }}$

22. Anderson ER, Murphy MP, Weymuller EA Jr. Clinimetric evaluation of the sinonasal outcome test16. Otolaryngol Head Neck Surg 1999;121:702-7. CrossRef

23. Ransom ER, Doghramji L, Palmer JN, Chiu AG. Global and disease-specific health-related quality of life after complete endoscopic resection of anterior skull base neoplasms. Am J Rhinol Allergy 2012;26: 76-9. CrossRef

24. Forner D, Hueniken K, Yoannidis T, et al. Psychometric testing of the Skull Base Inventory health-related quality of life questionnaire in multi-institutional study of patients undergoing open and endoscopic surgery. Qual Life Res 2021;30:293-301. CrossRef

25. Hopkins C, Gillett S, Slack R, Lund VJ, Browne JP. Psychometric validity of the 22-item Sinonasal Outcome Test. Clin Otolaryngol 2009;34:447-54. CrossRef

26. Morley AD, Sharp HR. A review of sinonasal outcome scoring systems - which is best? Clin Otolaryngol 2006;31:103-9. CrossRef

27. Schalek P, Otruba L, Hahn A. Quality of life in patients with chronic rhinosinusitis: a validation of the Czech version of SNOT-22 questionnaire. Eur Arch Otorhinolaryngol 2010;267:473-5. CrossRef

28. Browne JP, Hopkins C, Slack R, Cano SJ. The sinonasal outcome test (SNOT): can we make it more clinically meaningful? Otolaryngol Head Neck Surg 2007;136:736-41. CrossRef
29. Fliss DM, Gil Z. Atlas of Surgical Approaches to Paranasal Sinuses and the Skull Base. Berlin, Germany: Springer-Verlag GmbH; 2016.

30. Ebert C, Senior B. A review of minimally invasive pituitary surgery: the evolution from maximally to minimally invasive surgery. Otorinolaringologia 2009;59:97-105.

31. Sonnenburg RE, White D, Ewend MG, Senior B. The learning curve in minimally invasive pituitary surgery. Am J Rhinol 2004;18:259-63. CrossRef

32. Sheehan MT, Atkinson JL, Kasperbauer JL, Erickson BJ, Nippoldt TB. Preliminary comparison of the endoscopic transnasal vs the sublabial transseptal approach for clinically nonfunctioning pituitary macroadenomas. Mayo Clin Proc 1999;74:661-70. CrossRef

33. Ouaknine GER, Siomin V, Veshchev I, Razon N, Salame K, Stern N. The one-nostril transnasal transsphenoidal extramucosal approach: the analysis of surgical technique and complications in 529 consecutive cases. Oper Tech Otolaryngol Head Neck Surg 2000;11:261-7. CrossRef

34. Senior BA, Ebert CS, Bednarski KK, et al. Minimally invasive pituitary surgery. Laryngoscope 2008;118: 1842-55. CrossRef

35. Gil Z, Abergel A, Spektor S, Khafif A, Fliss DM. Patient, caregiver, and surgeon perceptions of quality of life following anterior skull base surgery. Arch Otolaryngol Head Neck Surg 2004;130:1276-81. CrossRef

36. Amit M, Abergel A, Fliss DM, Gil Z. The clinical importance of quality-of-life scores in patients with skull base tumors: a meta-analysis and review of the literature. Curr Oncol Rep 2012;14:17581. CrossRef

37. Gil Z, Abergel A, Spektor S, Shabtai E, Khafif A, Fliss DM. Development of a cancer-specific anterior skull base quality-of-life questionnaire. J Neurosurg 2004; 100:813-19. $\underline{\text { CrossRef }}$

38. Hanson M, Patel PM, Betz C, Olson S, Panizza B, Wallwork B. Sinonasal outcomes following endoscopic anterior skull base surgery with nasoseptal flap reconstruction: a prospective study. J Laryngol Otol 2015;129:S41-6. CrossRef

39. Yoo F, Kuan EC, Bergsneider M, Wang MB. Free mucosal graft reconstruction of the septum after nasoseptal flap harvest: a novel technique using a posterior septal free mucosal graft. J Neurol Surg B Skull Base 2017;78:201-6. $\underline{\text { CrossRef }}$ 